\title{
Market clearing price forecast for power peak shaving auxiliary service
}

\author{
Dunnan Liu ${ }^{1}$, Mengjiao Zou ${ }^{1,}$, Yue Zhang ${ }^{1}$,Lingxiang Wang ${ }^{1}$,Tingting Zhang ${ }^{1}$, and Mingguang Liu ${ }^{1}$ \\ ${ }^{1}$ School of Economics and Management, North China Electric Power University, Changping District, Beijing 102206, China
}

\begin{abstract}
The use of new energy to generate electricity in the power system and the large-scale increase of new energy grid connection has led to increasingly insufficient power system regulation,in order to solve this problem, the peak shaving auxiliary service market came into being.This article comprehensively analyzes the factors those affect the market clearing price of power peak shaving auxiliary services:The macro factors include energy economic policies (renewable energy and electric energy substitution), technological innovation, market operation rules, etc., and the micro factors include the quotation and demand of thermal power plants and wind power generation. The power peak shaving auxiliary service market is an important part of the power market. Its appearance makes the grid operation safer and more reliable, and the reasonable fluctuation of clearing prices and total market costs reflects the market's sensitivity to peak shaving resource demand.This paper uses the BP neural network model to select 31 consecutive days of peak shaving auxiliary service clearing price data in North China for prediction.
\end{abstract}

\section{Introduction}

In order to ensure the safe and stable operation of the North China Power Grid and the Beijing-Tianjin-Tangshan Power Grid, it is necessary to promote the optimization of the power auxiliary service resources of the North China Power Grid on a larger scale. Therefore, the relevant entities in the power system predict the market clearing price of auxiliary services, which is more conducive to the understanding of the new market situation for all power entities and facilitates efficient participation in market competition.

With the progress of the electricity reform, the electricity market has gradually been divided into the main energy market and the auxiliary service market, and the two markets need to be balanced to achieve the optimal configuration [1],The current energy consumption pattern is developing in the direction of "electricity substitution" and "clean substitution". The method of replacing coal with electricity and oil with electricity has optimized the energy consumption structure [2],however, the volatility of renewable energy will reduce the stability of the power system. As its installed capacity increases, the demand for power peak shaving auxiliary services will also increase [3].The price mechanism can be used to guide the peak of thermal power units to obtain profits [4]. Some scholars have proposed a two-part economic compensation mechanism and specific algorithm for peak shaving that combines peak shaving cost compensation and excess power generation revenue sharing [5].In foreign countries, Northern Europe uses the "ancillary service market + imbalance + settlement + regulation power market" model, the United Kingdom adopts the "integrated transaction" model, and the United States adopts the PJM. These models provide reference for my country's peak shaving auxiliary service market transactions. [6].The system marginal price, capacity cost and grid auxiliary service cost determine the electricity price level of the entire grid[8], the difference caused by the volatility of wind power output[10], coal consumption, loss, environment, fuel consumption, etc. will all have an impact on the cost of power peak shaving[7].

The market clearing price of peak shaving has the function of market guidance. A clear price signal attracts more units to provide peak shaving capacity to promote the effective consumption of clean energy in the receiving-end regional power grid [9].The importance of ancillary services has gradually increased in recent years and has not received much attention before. Therefore, there are relatively few domestic literatures on the clearing price prediction of the power peak shaving ancillary service market; There is no power peak shaving service in mature ancillary service markets abroad, and the time-sharing adjustment of the spot market electricity price has solved the peak shaving problem. Therefore, foreign research on this aspect is rare. Most of the forecasting models of electricity prices in the current literature predict short-term or medium- and long-term electricity transaction prices in the electricity market, such as:Using random forest regression to predict the price of spot market clearing [15], combined with support vector machine and autoregressive moving average and external input module hybrid mid-term power mcp prediction [12], applying generalized autoregressive sliding model to predict electricity prices [14], based on multiple support vector machines to build mid-term power mcp forecasting model [11], based on wavelet transform, chaotic least square support vector machines and exponential generalized autoregressive conditional

*Corresponding author: zoumengjiao_98@163.com 
heteroscedasticity model based day-ahead electricity price forecasting new technology [13].

Based on the above background, this article will analyze the factors that affect the clearing price of the peak shaving market from both the macro and micro aspects. Because the BP neural network has self-learning function and associative storage function, it can find the optimal solution at a high speed and has good forecast stability.This paper mainly uses the Bp neural network model to predict the clearing price of the peak shaving auxiliary service market.

\section{Macro factors}

\subsection{Energy Economic Policy}

In recent years, people's consumption demand has been increasing, and the upgrading of the consumption structure has promoted the continuous development of China's economy. However, because my country's current energy structure is mainly based on coal, the rapid energy consumption means that pollutant emissions are increasing year by year. The transformation of energy consumption patterns can start from both energy production and terminal consumption.

\subsubsection{Renewable Energy}

Affected by national policies, the installed capacity of renewable energy power generation has grown rapidly, but there are problems such as the high cost of renewable energy compared with traditional energy generation, the low flexibility of the power system, and the large-scale grid integration of renewable energy power generation. The intermittent, volatility and other characteristics of renewable energy itself have resulted in inefficient utilization of renewable energy. When renewable energy continues to develop, the market size increases, and the subsidy gap is further expanded, and the quota system emerges at the historic moment. At this time, in the absence of green certificate trading, the government compensates for corporate losses through subsidies; If green certificate trading is implemented, the price of renewable energy power is determined by the price of green certificates and the price of conventional energy power.In the peak shaving ancillary service market, the strong support of national policies and increased government subsidies are conducive to the increase of the supply-side renewable energy installed capacity and the reduction of electricity prices. Among them, the feed-in tariff subsidy policy has a significant impact on the installed capacity of wind power.

\subsubsection{Electricity alternative}

The State Grid proposed the development strategy of electric energy substitution in 2013. Compared with coal, oil and other energy sources, electric energy has the advantages of being safe, convenient, clean and efficient, and stable in supply. The current areas of electric energy substitution are very wide: electric heating, electric refrigeration, electric vehicles, households Electrification, electric kilns in industrial production, electrified railways, etc.However, it should be pointed out that the development of electric heating is not intended to replace central heating with combined heat and power. Electric heating is a supplementary heating method in the entire heating system. The vigorous implementation of the electric energy substitution policy has also promoted the continuous development of my country's electrification level. People's dependence on coal, gas and kerosene has weakened, and electric energy has met people's demand for coal and oil as a substitute. At the same time, the promotion of national policies, rewards, subsidies and other methods have stimulated the public's electricity demand, which has increased the demand-side electricity in the peak shaving auxiliary service market, and the electricity price may fall under the intervention of national policies.

\subsection{Technological innovation}

With the continuous expansion of the development and utilization of renewable energy in my country, the level of its technical equipment has been significantly improved. my country has mature large-scale hydropower design, construction, management and operation capabilities; low wind speed wind power technology has made breakthroughs and has been widely used in the Middle East and South; and established an internationally competitive photovoltaic power generation industry chain.Due to the influence of weather, season and other factors in the power generation process of clean energy, it is difficult for us to systematically control and predict the power generation and time of clean energy. At present, the problem of wind curtailment in my country's "Three Norths" area during the winter heating period is serious. This is because the proportion of combined heat and power units in the "Three Norths" area is high, which leaves less room for wind power. The flexibility of thermal power must be improved. At present, the flexibility of thermal power can be modified from two aspects: enhancing the flexibility of unit operation and enhancing the flexibility of boiler fuel. In the power peak shaving ancillary service market, innovations in power generation technology will reduce the cost of power generation, and thus electricity prices will fall to a certain extent, which will further stimulate demand and promote economic growth.

\subsection{Technological innovation}

The operating rules of the power peak-shaving auxiliary service market are an invisible hand used by the government to monitor the power peak-shaving auxiliary service market, which will affect the market demand and price of the peak-shaving service to a certain extent. Considering that the rapid development of photovoltaics in the Northeast region has a significant impact on the power system, on January 14, 2019, the new rules issued on the official website of the Northeast Energy 
Regulatory Bureau officially included photovoltaics in the power auxiliary service market. The Northwest region has a high penetration rate of new energy. According to its regional characteristics, the virtual energy storage mode and the adoption of the settlement method of "deep adjustment power generation rights substitution" were first established, which not only promoted the development of the market but also made the process more streamlined. In different regions, time periods, and unit types are different, there will be slight gaps in the compensation benchmark value and segmented quotation method of paid peak shaving.

\section{Micro factors}

\subsection{Quotation of thermal power plants and market demand}

The real-time electricity market is to encourage generators to participate in the regulation of power imbalances (under-generation management, over-generation management, congestion management). The quotation of thermal power plants sometimes refers to the quotation of the previous day's market (but whether the real-time market's quotation will be The market is high or the quotation deviation will be relatively large, it still depends on the supply and demand relationship), so the determination of the price mainly depends on the effectiveness of the real-time market price, that is, whether the price signal of the real-time market can adjust the supply and demand relationship. The market price is jointly determined by the supply side and the demand side: the quotations of thermal power plants are often relatively subjective and not very predictable; however, the peak shaving demand in the market is relatively objective. There are many factors that affect the demand for peak shaving in the market, such as: unit maintenance plan, cross-regional and cross-province power purchase, wind power generation, etc. However, the most important factor that will affect short-term price changes is the power of wind power, because wind resources are volatile and intermittent. In wind power generation, we need to pay attention to the conditions of wind resources, mainly wind speed and its stability. This is the determinant of the availability of wind resources, as well as the most basic factor that determines the amount of wind power and the cost of wind energy, and these factors will also have a negative effect on the final clearing price.

\subsection{Wind power}

The price of the power peak-shaving auxiliary service market fluctuates greatly, but because the fuel efficiency of thermal power units has not changed much in the short term and the current level of equipment in the market is relatively stable,I think thermal power units have little effect on prices, and the reason for the large price fluctuations is the use of new energy.Wind power and solar energy are all intermittent energy sources, and their power and quality of power generation are unpredictable in different seasons, time periods or due to changes in weather factors. The production, supply and consumption of wind power products are carried out almost at the same time, so the production and consumption of wind power must maintain a real-time balance.China's wind power resources are mainly concentrated in the "Three North" area, and its load has obvious reverse distribution characteristics. Wind power output has the characteristics of uncertainty, randomness and intermittent. The power grid considers its own ability to accept wind power and the safe operation of grid-connected power, and will limit part of the wind power output at a certain moment.

In recent years, the total installed capacity of wind power has steadily increased, and the wind power market has gradually become an important emerging market. However, whether wind power can be connected to the grid for power generation depends on whether the power system has sufficient peak shaving capacity.Due to the operation mode of cogeneration units "using heat to determine electricity", a large number of wind curtailments will occur during the heating season in northern my country.In the peak shaving ancillary service market, the efficiency of thermal power units will not change in the short term, and the cost of power generation will not change much in a short period of time. The results obtained by predicting short-periodical and highly volatile wind power generation power will affect the market peak shaving demand to a certain extent, thereby affecting the quotation of thermal power plants. If a large amount of wind power resources flood into the market during a certain period of time, the cost of wind power generation will be lower at this time because of the large supply, and the clearing price will also decrease.

\subsection{Selection of price influence factors}

As shown in Figure 1:analyze the factors that affect prices from both macro and micro aspects: once the macro policy of a region is determined, it is long-term and will not change much in the short term, Therefore, when predicting short-term prices, you can temporarily ignore the macro factors in this area. What needs to be considered is the micro factors that may change in the short term. Through the above analysis, it can be concluded that the wind power generation power is mainly considered among the micro factors. Short-term power prediction of wind power can improve the economic performance of system operation and increase the capacity of wind power absorption. For the power grid, accurate prediction is conducive to real-time adjustment of the power grid dispatching plan, reducing operating costs. For the electric field, it helps to ensure the grid connection rate of wind power and maximize the benefits. 


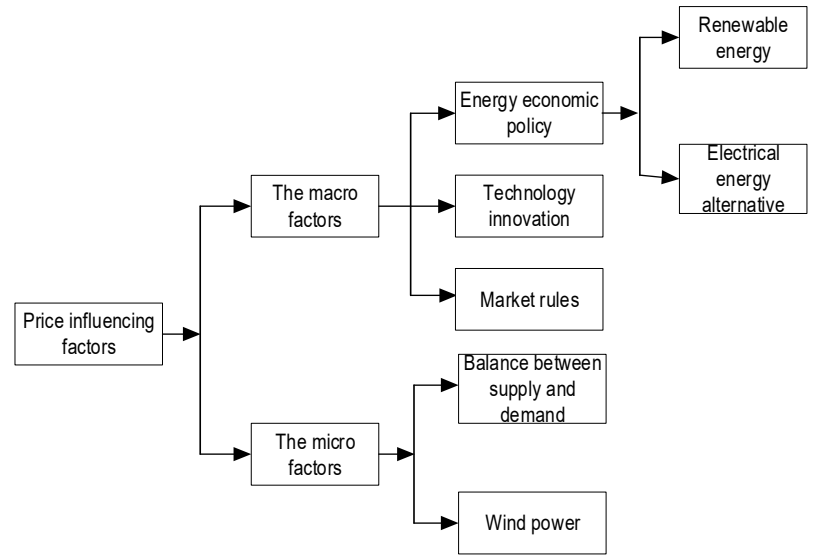

Fig. 1. Analysis of price influence factors

\section{Price Modeling of Peak-shaving Auxiliary Service Based on BP Neural Network}

The BP neural network includes input layer i, hidden layer $\mathrm{j}$, and output layer $\mathrm{k}$. The upper and lower layers are connected to each other but there is no connection between the same layers. There are network weights between the upper and lower neurons that indicate the connection strength of the two neurons $\omega$, the learning rate is $\eta$, The input vector is $\vec{X}=[x 1, x 2 \ldots x i \ldots x n], i=1,2, \ldots, n$; the output vector is $\vec{Y}=[y 1, y 2 \ldots y k \ldots y m], k=1,2, \ldots, m$; the output of each neuron in the t-th hidden layer is $\overrightarrow{\mathrm{a}}^{(\mathrm{t})}=\left[a_{1}^{(t)}, a_{2}^{(t)} \ldots a_{j}^{(t)} \ldots a_{s t}^{t}\right], j=1,2, \ldots, s t$.

Suppose the number of nodes in the input layer is $n$, the number of nodes in the hidden layer is 1 , and the number of nodes in the output layer is $\mathrm{m}$. The weight from the input layer to the hidden layer is $\omega_{\mathrm{ij}}$, the weight from the hidden layer to the output layer is $\omega_{\mathrm{jk}}$, the bias from the input layer to the hidden layer is ${ }^{\mathrm{a}_{j}}$, and the bias from the hidden layer to the output layer is ${ }^{b_{k}}$.Let $\omega_{i j}^{(\mathrm{t})}$ be the weight between the i-th neuron in the input layer and the $\mathrm{j}$-th neuron in the $\mathrm{t}$-th hidden layer, and $\mathrm{b}_{i}^{(t)}$ is the bias of the $\mathrm{i}$-th neuron in the $\mathrm{t}$-th layer, and there is a calculation formula:

$$
\begin{gathered}
\operatorname{net}_{i}^{(t)}=\sum_{j=1}^{s t-1} W_{i j}^{(t)} a_{i j}^{t-1}+b_{i}^{(t)} \\
\mathrm{a}_{i}^{(t)}=f\left(\text { net }_{i}^{t}\right)
\end{gathered}
$$

Where net $_{i}^{(t)}$ is the input of the i-th neuron in layer $\mathrm{t}$, and $\mathrm{f}(\bullet)$ is the activation function.

The output of the hidden layer is:

$$
H_{\mathrm{j}}=g\left(\sum_{i=1}^{n} \omega_{i j} x_{i}+a_{j}\right)
$$

The output of the output layer is:

$$
O_{K}=\sum_{j=1}^{1} H_{j} \omega_{j k}+b_{k}
$$

$$
\begin{aligned}
& \text { CIf there are } \mathrm{m} \text { training samples: } \begin{array}{ccccc}
\mathrm{x}_{1} & \mathrm{r}_{1} & \ldots & \mathrm{y}_{1} \\
x_{2} & r_{2} & \ldots & y_{2} \\
\cdots & \ldots & \ldots & \cdots \\
& x_{\mathrm{m}} & \mathrm{r}_{m} & \cdots & \mathrm{y}_{\mathrm{m}}
\end{array} \\
& d_{i} \text { is the expected output of } x_{i} \text {, define the error as: } \\
& E=\frac{1}{m} \sum_{i=1}^{m} E(i)
\end{aligned}
$$

Where $E(i)$ is the training error of a single sample:

$$
E(\mathrm{i})=\frac{1}{2} \sum_{k=1}^{n}\left(d_{k}(i)-y_{k}(i)\right)^{2}
$$

When the error is $\mathrm{X}$, the error is fed back from the back neuron level by level, and the Bp neural network will iteratively update the weight and bias during the feedback process, the way is:

$$
\begin{gathered}
W_{\mathrm{i} j}^{(t)}=W_{\mathrm{i} j}^{(t)}-\alpha \frac{\partial E}{\partial W_{i j}^{(t)}} \\
\mathrm{b}_{i}^{(t)}=\mathrm{b}_{i}^{(t)}-\alpha \frac{\partial E}{\partial b_{i}^{(t)}}
\end{gathered}
$$

\section{Case analysis}

In order to verify the effectiveness of the peak shaving auxiliary service clearing price model based on BP neural network proposed in this paper, this paper uses the peak shaving auxiliary service clearing price in North China to verify.Select electricity price data for 31 consecutive days, with 15 minutes as a step, a total of 96 points per day, but there are only 40 time points for the implementation of the transaction, that is, 26 time points in the 0:45-7:00 time period and 12:45 -16: 00 time period 14 points. The data obtained are: North China. Jingjintang load (MW), North China. Jingjintang wind power total active power (MW), North China. Jingjintang photovoltaic output (MW), clearing price (yuan/MWH).

The 40 time points of each day are cycled from 1-40 as the time points of the corresponding data.Then determine the week attribute of the corresponding data day and whether it is a holiday, but through analysis, it is found that the correlation between the weekly attribute of the corresponding data and whether it is a holiday is not very relevant to the clearing price, Therefore, these two types of data were not considered when constructing the prediction model.In the Bp neural network prediction model, the time point, North China. Jingjintang load (MW), North China. Jingjintang total active power (MW), and North China. Jingjintang photovoltaic output (MW) are used as input layers. The clearing price are used as the final output layer. The data of the first 30 days are training examples, and the clearing price on the 31 st day is a test example that is predicted. The predicted results are shown in Figure 2 and Figure 3: 


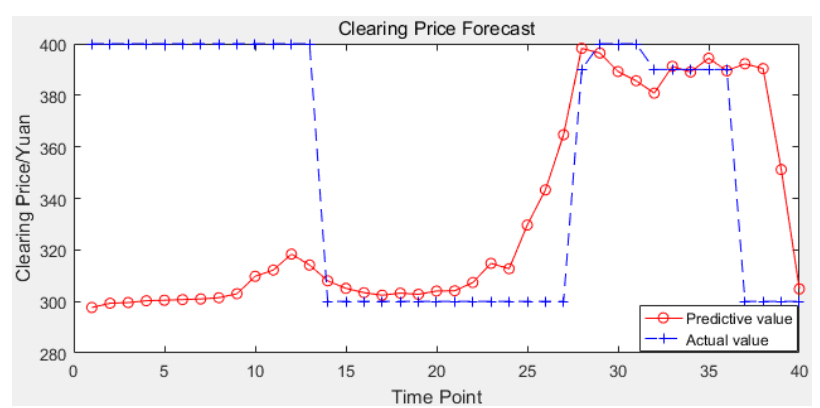

Fig. 2. Clearing price forecast

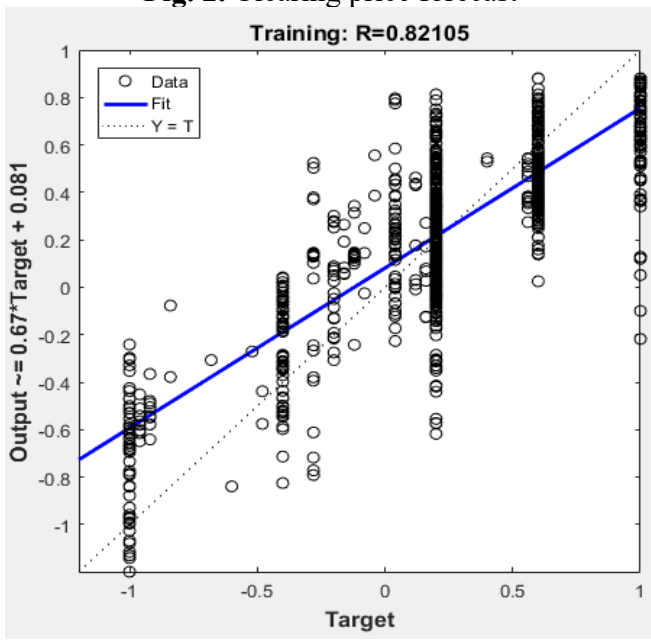

Fig. 3.Correlation coefficient

From the prediction result in Figure 2, we can see that the average absolute percentage error (MAPE) between the actual value of the clearing price on the 31 st day and the predicted value is $11.8016 \%$. The image shows that from the 14th time point onwards, the change trend of the actual value curve and the predicted value curve is roughly the same, the values are also relatively similar, and the prediction effect is generally satisfactory.

\section{Conclusion and Outlook}

In combination with this article, the following conclusions are obtained: the emergence of the power peak shaving auxiliary service market is to solve the problem of the imbalance between the supply and demand of electrical energy in the power system during a certain period of time. Compared with the US PJM model, which uses changes in real-time electricity prices to guide power generation companies to actively participate in peak shaving: the income of generator sets with different load rates is reflected and adjusted by changes in real-time electricity prices in the energy market during different periods.Most areas of China have not yet established a spot market based on time-of-use electricity prices, so China's peak shaving is achieved through the power peak shaving auxiliary service market.There are many factors that affect the clearing price. The macro factors include energy economic policies, technological innovation, market operation rules, etc., and the micro factors include the quotation and demand of thermal power plants and the power of wind power.After a comprehensive analysis, it is found that the most important factor affecting the market clearing price of peak shaving auxiliary services is wind power.In the process of predicting the clearing price through the BP neural network, it is found that the clearing price sequence of the power peak shaving auxiliary service market is highly volatile, and it is difficult to find the periodic law of the sequence.

This article analyzes the factors that affect the market clearing price of peak shaving auxiliary services, and uses BP neural network to predict clearing prices. However, due to time constraints, there is still room for improvement in the following aspects: the analysis of influencing factors in this article is qualitative analysis, it is also possible to further analyze wind power generation power from climatic factors such as temperature, humidity, wind direction, wind speed, and in-depth analysis of the correlation between various influencing factors and clearing prices; the current input data uses full-time data, which is difficult to reflect the error of market prices; there is a value of 0 in the data, and its processing method needs to be further studied; the prediction level achieved by the model used in this article is not high enough, and further optimization or exploration of more suitable models is needed.

\section{Reference}

1. G. Yang. Research on Joint Optimization Decision of Electric Energy Main Market and Auxiliary Service Market[D],SJTU(2011)

2. G. Huang .Research on the Development Potential of Electric Energy Substitution and Its Economic and Environmental Benefit[D],NCEPU(2019)

3. X.L.Zhao, M.Wang, Y.Zhao, Q.B.Wu. Improved model of compensation mechanism for peak shaving auxiliary service based on capacity difference of thermal power units $[\mathrm{J}]$. Automat Electron Power Sys.04:57-61(2013)

4. H.P.Zhang, D.B.Gao, J.N.Zhang, Z.Xu. The Development Road of Northeast Electric Power Peak Shaving Auxiliary Service Market[J].China Power Enterprise Management, 28:26-29(2018).

5. Y.S. Zhang, J.Zhang, T.T.Feng. Research on th -e Economic Compensation Mechanism of China's Nuclear Power Plants' Peak Shaving Auxiliary Service[J].Power Syst Technol.07:2131-213 8(2017)

6. Y.H. He, M.Zhou, Z.Y.Long, J.Xu.The operation mode of typical foreign electricity balance market and its enlightenment to China $[\mathrm{J}]$. Power Sys Techno.11:3520-3528(2018)

7. L.Qi, B.Cheng, R.Zhao, X.J.Gao.Cost and benefit analysis of providing peak shaving auxiliary services for coal-fired thermal power units[J].Power Syst and Big Data,10:23-29(2019)

8. P.S.Dai.Research on the Price Formation Mechanism of China's Electricity Market[D].XMU(2004)

9. F.Xu, C.Q.Ge, X.Wu, M.J.Zhu, M.F.Tu.The market mechanism and clearing model of peak shaving auxiliary services in regional power 
grids $[\mathrm{J}]$,Automat $\quad$ Electron Power Sys.16:109-120(2019).

10. J.F.hu.Research on Cost Allocation Mechanism and Model of Auxiliary Services for Wind Power Access[D].NCEPU(2014)

11. Xing Y,Nurul A. Chowdhury. Mid-term electricity market clearing price forecasting: A multiple SVM approach[J].Int J Electr Power Energy Syst.58(2014).

12. Xing Yan,Nurul A. Chowdhury. Mid-term electricity market clearing price forecasting utilizing hybrid support vector machine and auto-regressive moving average with external input $[\mathrm{J}]$. Int J Electr Power Energy Syst.63(2014).

13. Zhang JL, Tan ZF. Day-ahead electricity price forecasting using WT, CLSSVM and EGARCH model. Int J Electr Power Energy Syst.45:3628(2013).

14. X.C.Liu, J.Shen, Y.G.Li. A Generalized Auto-Re gressive Conditional Heteroscedasticity Model fo $r$ System Marginal Price Forecasting Based on Weighted Double Gaussian Distribution[J].Pow-e r Sys Techno ,1:139-144(2010).

15. Q.Wei,S.J.Cheng,W.B.Huang,G.W.Ma,C.H.Tao.Fo recasting method of spot market clearing price based on random forest regression,Proc Chin Soc Electrical Eng,1-10(2020). 